\title{
The Humanities in process, not crisis Information literacy as a means of low-stakes course innovation
}

ibrarians and humanists these days share several concerns: the nature and value of expertise, our relationship to texts/textual production, and traditional and emerging approaches to the study, collection, and preservation of canonical and alternative cultural content. At the moment, debates about these matters are often construed as a crisis of relevance and cause for much hand-wringing. While digital humanities projects offer creative approaches to these issues on a large scale, they have not always articulated pedagogical approaches relevant to undergraduate learners, especially at smaller institutions. ${ }^{1}$

By examining "the humanities" from another angle-innovative teaching and learning at the undergraduate level through the incorporation of information literacywe find a different narrative about ways that humanities faculty are engaging these trends productively and in pedagogically interesting ways. Although there are several studies within library literature about how non-librarian faculty conceptualize information literacy, ${ }^{2}$ we do not know as much about how faculty who have adopted an ACRL Standards-based definition go about putting it to work in their courses and assignments.

While we have some insight on the integration of information literacy and the humanities broadly conceived thanks to articles like Ellen Daugman, Leslie McCall, and Kaeley McMahan's "Designing and implementing an information literacy course in the
Humanities," most research and reporting on information literacy in the humanities focuses on course-specific and/or librarianled efforts. ${ }^{3}$ But how do nonlibrarian faculty adopters of information literacy in the humanities incorporate information literacy in a variety of disciplines? What are their conclusions about the results of this effort?

\section{Institutional context}

I will give a brief description of the institutional context to help situate answers to these questions. Trinity University in San Antonio, Texas, enrolls about 2,600 students. As of this writing, we are completing the fifth year of a SACS-approved Quality Enhancement Plan centered on information literacy. ${ }^{4}$ This plan includes a modified version of the ACRL Information Literacy Competency Standards for Higher Education 5 with five discrete student learning goals: access, understand, evaluate, use ethically, and create, ${ }^{6}$ which we have used to help demystify the language of information literacy and break information literacy learning into smaller, more easily assessable chunks. The strategies and components of this plan have been previously reported on by Michelle Millet and others. ${ }^{7}$ As part of this program over the last five years, fac-

Anne Jumonville is information literacy librarian at Trinity University, e-mail: ajumonvi@trinity.edu (c) 2014 Anne Jumonville 
ulty revised or developed 37 courses in the arts or humanities to better incorporate information literacy learning. These courses were developed or re-designed at all levels (introductory to advanced) in Art and Art History, Classics, English, History, Theater, Music, Philosophy, Religion, Modern Languages, and interdisciplinary areas of study. Assignments were designed for majors as well as students meeting general education requirements. I will focus on two of the most frequently used strategies for incorporating or developing information literacy learning opportunities in a course assignment: annotated bibliographies and online discussion forums.

\section{Integrating information literacy, Strategy 1: Annotated bibliographies}

The popular use of annotated bibliographies or other types of annotated source assignments belies the variety of approaches to such an assignment. In other contexts college educators have written positively about annotated bibliographies for the degree to which they can serve as "an opportunity for students to review the literature on their selected topic and then to receive feedback about the direction of their research and the quality of the sources they are using."

In other words, the annotated bibliography serves as an efficient means for instructors to give students a better idea of how they're doing. This is certainly the case at Trinity. As one instructor wrote, "The annotated bibliography enabled me as a professor to point out some of the areas (information literacy aspects and other analytical skills) students needed to seriously reconsider in the conception of their final papers...after receiving comments on their annotated bibliographies, most of my students developed clearer topics and theses, and also established more explicit dialogues with academic sources."

Nearly three-quarters of the redesigned humanities courses at Trinity included some form of annotated bibliography assignment as a means for enhancing information literacy learning. While a few instructors focused on students' abilities to evaluate how useful a particular source was for the topic or in preparing an original argument, the majority of assignments prompted students to evaluate the academic credibility and significance of the source on its own terms. In a few cases, instructors also hoped to use an annotated bibliography assignment as a check against plagiarism in final papers. Another interesting addition some instructors employed was to ask students to reflect on the research process as part of the annotation.

\section{Adding an innovative twist}

Faculty members' assessments of student work indicated that traditionally conceived annotated bibliographies were an effective means of providing a check point for students as they learned about a topic. Instructors were able to see what types of sources students were considering for future work and to gain a sense of how well students were able to evaluate the relevance and credibility of a particular author or work. At the same time, some courses made use of components of the annotated bibliography in even more innovative ways.

Three instructors worked with an instructional designer to create a technology-enhanced version of an annotated bibliography assignment. In those courses, students created web pages with annotated, hyperlinked commentaries that explicated a specific passage of primary text. Students used links to direct the reader to relevant primary and secondary source annotations for individual phrases and terms while also demonstrating close reading and analytical writing skills.

As one instructor wrote about student success on this assignment, "I believe the revised webpage assignment is a great improvement...in the past, I have had less than a $25 \%$ rate on the information literacy goals of access and ethical use of appropriate sources. With the redesigned assignment, I have nearly doubled that rate." 


\section{Persistent challenges}

In terms of overall challenges, students appeared to have more trouble when the assignment required annotations in one format (writing) and a related final product in another (e.g., an oral presentation). They were less likely in those situations to effectively integrate or make use of the sources that they had worked with previously. At the same time, for language courses in which oral communication is a key skill, a written annotated bibliography connected to an oral presentation still focused student attention on higher-quality sources, even as their integration of those sources in a presentation was not always successful. Finally, while many instructors were pleased to see students producing high-quality work on final papers or presentations for the course after completing an annotated bibliography assignment first, not all were able to determine whether it was the annotated bibliography assignment or other course changes that made the difference.

\section{Integrating information literacy, strategy 2: Online discussion forums}

Using an online discussion forum with information literacy-related prompts was another successful method and one that could be combined with variations on the annotated bibliography.

For example, several assignments asked students to locate, present, and discuss additional sources relevant to the topic of conversation on a class blog or Blackboardstyle course discussion forum. In a creative variation, one instructor asked students to compile and "tag" source annotations on the blog in order to use the same blog with future iterations of the course; her goal was that the addition of the tagging process would help students be more aware of the importance of "making [work] recognizable to others interested in related products."

\section{Impact on Student Engagement}

Three of the instructors who used a discussion forum to enhance information literacy commented on the ways in which this "lowstakes" approach changed other aspects of the class in other positive ways. For example, one instructor found her assignment—which involved using the required course readings to be a "springboard for researching related academic articles" as part of students' participation homework - "enhanced student involvement" and "added depth to the course." In terms of overall skills assessment, one instructor who was less pleased with students' ability to cite sources properly in the final paper found that "in [the ongoing, lower-stakes blogging forum] I found the students' use of properly citing their sources very successful." That instructor also employed an interesting alternative to the class blog; instead of working primarily through text and seeking out other articles and books to bring in to the discussion, students improved their visual literacy by locating, posting, and discussing images related to the course content.

\section{Noted improvements in student learning}

Two other instructors also found that repeating a short assignment, such as a weekly reflection, in which students understood that referencing citing sources correctly was a significant requirement resulted in improvements in their abilities to do so by the end of the semester. Other instructors noted improvements in the quality of student contributions overall. In observing the degree to which discussion quality had improved throughout the semester, one instructor mentioned students' demonstrated increased levels of understanding, evaluative ability, and creativity. In her words, "due to the weekly reflections, students were able to synthesize their ideas [about the course topics] and use effectively the information from the readings and discussions."

\section{Information literacy as a lens and a bridge to innovative learning in the Humanities}

Integrating information literacy into humanities courses does not have to involve a totally new set of assignments, although it certainly 
can. The assignments presented here can be scaled up or down, depending on class size, course goals, and other institution-specific factors. Seemingly simple strategies, such as asking students to bring their own sources to bear on a regular course discussion forum topic or asking them to annotate a list of potential sources prior to embarking on a more significant research paper, can help instructors gauge student progress toward information literacy development.

At the same time, such strategies can also provide a bridge toward technologically enhanced twists on traditional assignments, such as an annotated class blog instead of individually compiled annotated bibliographies. Evidence from courses at Trinity indicates that these strategies can not only increase students' information literacy abilities and overall engagement in humanities courses, but also provide instructors with additional means of assessment and the opportunity to integrate new technologies in their assignments.

\section{Notes}

1. Stephen Brier, "Where's the Pedagogy?: The Role of Teaching and Learning in the Digital Humanities," Debates in the Digital Humanities, edited by Matthew K. Gold (Minneapolis: University of Minnesota Press, 2012), 390-401.

2. Laura Saunders, "Faculty Perspectives on Information Literacy as a Student Learning Outcome," Journal of Academic Librarianship 38, no. 4 (07/01, 2012): 226-236, doi: 10.1016/j.acalib.2012.06.001. Sheila Cunningham, Allison Carr, and Stephanie Sterling Brasley, "Uncovering the IL Disconnect: Examining Expectations among Librarians, Faculty and Students," Paper presented at the ACRL National Conference, Philadelphia, Pennsylvania, April 2011. Shelley Gullikson, "Faculty Perceptions of ACRL's Information Literacy Competency Standards for Higher Education," Journal of Academic Librarianship 32, no. 6 (11/01, 2006): 583-592, doi: 10.1016/j.acalib.2006.06.001.

3. Kathleen A. Abromeit and Victoria Vaughan, "Info Lit and the Diva: Integrating
Information Literacy into the Oberlin Conservatory of Music Opera Theater Department," Notes 60, no. 3 (03, 2004): 632-652. Rina Vecchiola, "Using ARLIS/NA Information Competencies for Students in Design Disciplines in Course Integrated Information Literacy Instruction at Washington University in St. Louis," Art Documentation: Bulletin of the Art Libraries Society of North America 30, no. 1 (Spring 2011, 2011): 74-78. Randall Studstill and Peggy Cabrera, "Online Primary Sources in Religious Studies: Active Learning Exercises for Information Literacy Instruction," Journal of Religious \& Theological Information 9, no. 3 (07, 2010): 84-112, doi:10.1080/10477845. 2010.527252.

4. Trinity University, Expanding Horizons: Using Information in the 21st Century: A Quality Enhancement Plan for Trinity University, 2008-2013, prepared for the Southern Association of Colleges and Schools Commission on Colleges, February 2008, accessed November 7, 2012, www.trinity.edu /departments/academic_affairs/qep /ExpandingHorizonsQEPpublic.pdf.

5. Association of College and Research Libraries, "Information Literacy Competency Standards for Higher Education," 2000, accessed November 7, 2012, www.ala.org/acrl /standards/informationliteracycompetency.

6. Trinity University, Expanding Horizons: Using Information in the 21st Century.

7. Megan Oakleaf, Michelle S. Millet, and Leah Kraus, "All Together Now: Getting Faculty, Administrators, and Staff Engaged in Information Literacy Assessment," portal: Libraries and the Academy 11, no. 3 (2011): 831-852, doi: 10.1353/pla.2011.0035. Michelle S. Millet, Jeremy Donald, and David W. Wilson, "Information Literacy Across the Curriculum: Expanding Horizons," College \& Undergraduate Libraries 16, no. 2/3 (April 2009): 180-193, doi: 10.1080/10691310902976451.

8. Christy R. Stevens and Patricia J. Campbell, "Collaborating with Librarians to Develop Lower Division Political Science Students' Information Literacy Competencies," Journal of Political Science Education 4, no. 2: 225252, doi: 10.1080/15512160801998114. n 